\title{
NÍVEL DE CONHECIMENTO DE AGRICULTORES FAMILIARES EM RELAÇÃO AO USO DE AGROTÓXICOS EM UM MUNICÍPIO DO INTERIOR DA BAHIA
}

\author{
LEVEL OF KNOWLEDGE OF FAMILY FARMERS IN RELATION TO THE USE OF \\ AGROTOXIC IN A MUNICIPALITY IN THE INTERIOR OF BAHIA \\ Raíssa Amaral Oliveira ${ }^{1}$, Cassiara Camelo de Souza ${ }^{2}$, Dioneire Amparo dos Anjos ${ }^{2}$, Clavdia \\ Nicolaevna Kochergin ${ }^{2}$, Márcia Elena Zanuto \\ Universidade Federal da Bahia ${ }^{1}$, UFBA Campus Anísio Teixeira - Instituto Multidisciplinar em Saúde ${ }^{2}$
}

\begin{abstract}
The expansion in the use of pesticides is due to the insertion of new technologies that aim to promote an increase in productivity rates in rural areas, fighting pests that compromise agricultural production, with occupational exposure being increasingly exacerbated, which can cause acute poisoning to farmers. The objective was to evaluate the level of knowledge of family farmers in relation to the use of pesticides. from a cross-sectional study with the application of a semi-structured form, presenting 31 interviews carried out in the Rural Workers Union (STR) in the municipality of Vitória da Conquista - BA, in 2017, with family farmers, finding that the population groups most vulnerable to occupational exposure by pesticides are women and the elderly and that low education influences the understanding of the information contained on product packaging labels; most consider that the chemical substance is dangerous to human health, however, those who use pesticides reported not using Personal Protective Equipment (EPIS's). This work presented relevant results, highlighting several problems that are still persistent in the field in relation to the level of knowledge of family farmers in relation to the use of pesticides, making it necessary to carry out management of Health/Environmental Education actions.
\end{abstract}

Keywords: Pesticides; Rural workers; Family farming.
Resumo

A expansão na utilização de agrotóxicos ocorre devido à inserção de novas tecnologias que visam promover o aumento nas taxas de produtividade no meio rural combatendo pragas que comprometem a produção agrícola, sendo a exposição ocupacional cada vez mais exacerbada, podendo provocar intoxicações agudas aos agricultores. Objetivou-se avaliar o nível de conhecimento dos agricultores familiares em relação ao uso de agrotóxico. a partir de um estudo transversal com aplicação de formulário semiestruturado, apresentando 31 entrevistas realizadas no Sindicato dos Trabalhadores Rurais (STR) do município de Vitória da Conquista - BA, em 2017, com agricultores familiares, constatando que os grupos populacionais mais vulneráveis à exposição ocupacional por agrotóxicos são as mulheres e idosos e que a baixa escolaridade influencia na compreensão das informações contidas nos rótulos das embalagens dos produtos; a maioria considera que a substância química é perigosa para a saúde humana, no entanto, os que utilizam agrotóxicos informaram o não uso dos Equipamentos de Proteção Individual (EPIS's). Este trabalho apresentou resultados relevantes, destacando vários problemas ainda persistentes no campo em relação ao nível de conhecimento de agricultores familiares em relação ao uso de agrotóxicos, sendo necessária a realização de gerenciamento de ações de Educação em Saúde/Ambiental.

Palavras-chave: Agrotóxicos; Trabalhadores Rurais; Agricultura Familiar. 
O uso de agrotóxicos no Brasil teve início na década de 1950, acompanhando um uso sistematicamente mais intensivo de insumos químicos e mecanização dos processos produtivos, pelos países em desenvolvimento. ${ }^{1,2}$ A expansão da utilização de agrotóxicos esteve atrelada à inserção de novas tecnologias que visavam promover aumento da produtividade agrícola. Assim, nas últimas décadas, o Brasil vem ocupando a liderança mundial no consumo de agrotóxicos. ${ }^{1-5}$

A exposição a estes compostos pode desencadear agravos à saúde com ocorrência de sintomas agudos ou crônicos. A exposição aguda apresenta sintomas tais como: falas desconexas, tremores, dificuldade respiratória, fraqueza, mal estar, dores de cabeça, tonturas, vertigem, alterações visuais, salivação, sudorese aumentada, náuseas, vômitos, além de perda de consciência, podendo chegar ao coma ${ }^{1,6}$ que aparecem logo após o contato direto com os diferentes compostos. Por sua vez a exposição crônica, caracteriza-se pelo contínuo contato com o agrotóxico a baixas concentrações e frequência prolongada ao produto. ${ }^{7}$ De maneira geral, a exposição crônica pode acarretar o desenvolvimento de diversos tipos de cânceres, más formações fetais, danos para o sistema nervoso e também para o funcionamento do sistema endócrino. ${ }^{4,5,8}$

Os agricultores não se atentam para os riscos relacionados ao manuseio dos agrotóxicos, limitando-se às informações contidas nos rótulos dos produtos. ${ }^{1}$ Afirmam ter noção da agressividade dos produtos, mas aceitam a exposição contínua como um fator inerente à sua profissão relativizando o fato ou não associando alguns sintomas agudos apresentados com uma possível intoxicação pela utilização de agrotóxicos. ${ }^{8,9}$ Além disso, uma grande dificuldade é que muitos agricultores utilizam vários tipos de produtos, muitas vezes misturados, impossibilitando especificar o efeito nocivo de cada um aos indivíduos diretamente expostos. Basicamente, a principal problemática que envolve os agravos à saúde pelo uso de agrotóxicos, principalmente por tempo prolongado, é o retrato da intoxicação aguda, pois, mascara os riscos de doenças crônicas associadas. $^{3}$

Estima-se que, dentre os trabalhadores rurais de países em desenvolvimento, os agrotóxicos causem 70 mil intoxicações anuais que podem evoluir para óbito, sendo as intoxicações agudas, a face mais visível do impacto destes produtos na saúde. No Brasil, dados do Sistema
Nacional de Informação Tóxico-Farmacológica (SINITOX), demonstraram que entre 2009 e 2013, foram registrados 33.028 casos de intoxicação aguda por agrotóxicos de uso geral. Destes, aproximadamente 700 casos, que corresponde a $31 \%$ do total mencionado, foram registros de óbitos ocasionados por intoxicação com agrotóxicos utilizados na atividade agrícola. Em 2017, este número não se alterou muito, correspondendo a $30,50 \%$ dos óbitos. ${ }^{10}$

O uso seguro dos agrotóxicos é sustentado pelas possíveis medidas de controle quanto aos riscos na manipulação desses produtos. Assim sendo, caso fosse realizada com eficácia as medidas de segurança para a minimização dos efeitos, a utilização de agrotóxicos tornar-se-ia mais segura, baseada nos procedimentos de proteção indicados que devem ser adotados durante a manipulação e nas regras gerais de biossegurança. ${ }^{2,11}$ Porém, na maioria das situações, inexiste um controle eficaz sobre a comercialização e uso destes produtos, os equipamentos de proteção individual (EPI's) não são usados de modo rotineiro, não há monitoramento da exposição ocupacional e o diagnóstico e tratamentos dos casos de intoxicação são falhos. ${ }^{12}$

Em 2019, no Brasil, houve mudanças na política de liberação de novos agrotóxicos e da reconfiguração da classificação toxicológica, facilitando a maior disponibilidade de princípios ativos. $^{13}$ O primeiro impacto observado é em relação aos trabalhadores rurais, que nem sempre são capacitados para o manuseio de agrotóxicos e são expostos de forma excessiva, sem a devida informação dos riscos a sua saúde. ${ }^{14}$

Muito embora a pesquisa sobre o impacto do uso de agrotóxicos sobre a saúde humana tenha crescido em anos recentes, é insuficiente para o conhecimento da extensão da carga química de exposição ocupacional e da dimensão dos danos à saúde, decorrentes do uso intensivo de agrotóxicos $1,3,13$, principalmente em pequenos produtores rurais, como os agricultores familiares. Agricultor familiar é aquele que pratica atividades no meio rural, em área de até quatro módulos fiscais (unidade territorial agrária que varia de 5 a 100 hectares, definida pela Lei no 6.746/79), utilizando predominantemente, mão de obra da própria família, sem auxílio técnico e tendo um percentual mínimo da renda familiar originado de atividades econômicas do seu próprio estabelecimento. ${ }^{15}$

Sabendo-se que na região Nordeste, a "seca" é o principal fenômeno climático enfrentado e a agricultura irrigada apresenta-se como a estratégia no processo de desenvolvimento da modernização agrícola com concomitante 
utilização de agrotóxicos, oferecendo condições favoráveis ao desenvolvimento de diferentes produtos durante o ano. ${ }^{16} \mathrm{E}$, que o uso inadequado de agrotóxicos tem sido citado como causa mais importante de intoxicações e morte no Brasil com destaque para região Nordeste. ${ }^{17} \mathrm{O}$ presente estudo avaliou o nível de conhecimento de agricultores familiares de um município do interior da Bahia, sobre o adequado uso de agrotóxicos.

\section{Metodologia}

Trata-se de um estudo transversal, descritivo com abordagem quantitativa, realizado no primeiro trimestre de 2017 , com a participação de agricultores familiares, residentes na zona rural de Vitória da Conquista- BA, e vinculados ao Sindicato dos Trabalhadores Rurais do município mencionado (população-alvo), a coleta foi realizada na sede do referido Sindicato, mediante autorização.

O estudo foi aprovado pelo Comitê de Ética e Pesquisa em Seres Humanos do Instituto Multidisciplinar em Saúde da Universidade Federal da Bahia (CEP - IMS/UFBA), sob parecer número 1.966.257.

Para coleta dos dados foi utilizado um instrumento semiestruturado, baseado em instrumentos desenvolvidos por Jacobson et al $(2009)^{15}$, Rangel e colaboradores $(2011)^{8}$, Preza e Augusto (2012) ${ }^{4}$ e pela Pesquisa Nacional de Saúde $(P N S)^{19}$ com algumas modificações. Este foi composto por eixos de perguntas: A Características gerais do domicílio; B Características gerais do entrevistado; C Informações sobre produção e uso de agrotóxicos na lavoura; D - Informações gerais da produção; E Informações sobre a saúde do agricultor.

O trabalho teve como critérios de inclusão, agricultores familiares maiores de 18 anos, de ambos os sexos, residentes nos limites territoriais da zona rural do município, que trabalhassem na propriedade da família e que estivessem presentes no interior do espaço físico do Sindicato dos Trabalhadores Rurais do município. Como critério de exclusão, foi a idade menor que 18 anos dos trabalhadores rurais.
Entre os dias 04 e 10 de abril de 2017, realizou-se a coleta dos dados do estudo, por meio de abordagem individual aos agricultores presentes na sede do Sindicato dos Trabalhadores rurais do Município de Vitória da Conquista/BA. No momento da entrevista o pesquisador entregou uma cópia do TCLE e leu seu conteúdo em voz alta, esclarecendo possíveis dúvidas e coletando a assinatura do agricultor ou a impressão dactiloscópica, conforme concordância em participar do estudo.

Os dados coletados foram inseridos em banco de dados eletrônico e analisados por meio do programa Epi Info ${ }^{\circledR}$ (versão 7), totalizando trinta e um (31) indivíduos que concordaram em participar do estudo. Foi realizada a análise descritiva do perfil dos entrevistados, das características gerais do domicílio, das informações relacionadas ao uso de agrotóxico na lavoura, do padrão de produção e uso de agrotóxicos, bem como das informações a respeito da saúde do agricultor.

\section{Resultados}

Na Tabela 1, estão dispostos os dados referentes às características sociodemográficas dos agricultores familiares entrevistados. Do total de 31 indivíduos que responderam ao formulário, 58\% foram mulheres, $58 \%$ referiram ser de cor/raça parda e $48,3 \%$ encontravam-se na faixa etária de idade entre 61 e 80 anos, com a média de idade de 60 anos.

Em relação ao nível de escolaridade, todos relataram ter sido alfabetizados. Foi possível verificar que $41,9 \%$ dos entrevistados cursaram o ensino Fundamental I de forma regular e 32,2\% frequentaram classes de alfabetização, considerouse também, outras formas de elevação do nível de escolaridade como, por exemplo, o programa de Educação de Jovens e Adultos (EJA) e/ou supletivo. Em síntese, 90,2\% não concluíram o ensino fundamental.

Tabela 1 - Perfil dos agricultores familiares participantes do estudo, Município de Vitória da Conquista- BA, 2017.

Características gerais dos agricultores familiares $\quad n=31 \quad$ Percentual \%

\begin{tabular}{lll}
\hline Gênero & & \\
Masculino & 13 & 41,9 \\
Feminino & 18 & 58,0
\end{tabular}




\section{Cor/Raça}

Branca

Negra

Parda

\section{Faixa Etária}

18 a 40 anos

41 a 60 anos

61 a 80 anos

\section{Escolaridade}

Fundamental I Incompleto $\quad 13 \quad 41,9$

Fundamental II Incompleto

Ensino Médio

\section{Curso mais elevado que frequentou}

Classe de Alfabetização

Alfabetização de jovens e adultos

Regular do ensino fundamental

Educação de jovens e adultos (EJA) ou supletivo $1^{\circ}$ grau

Dentre os entrevistados, $87,1 \%$ residiam predominantemente em casas, com uma média de quatro (04) pessoas por domicílio. A principal forma de fornecimento de água ao domicílio foi à rede geral de distribuição (Embasa $\left.{ }^{\circledR}\right) \quad(35,4 \%)$, seguida do provimento por meio de "carros-pipa" $(25,8 \%)$. Além da forma principal, $58 \%$ dos entrevistados, responderam não haver outro modo de abastecimento de água no seu domicílio. E quanto ao tratamento prévio da água utilizada para beber, a forma mais referida foi a filtrada $(67,7 \%)$, entretanto, $19,3 \%$ responderam que bebiam água sem nenhum tratamento.

Em relação ao destino dado ao lixo comum na propriedade, $58 \%$ relataram que queimavam e, apenas $32,6 \%$ referiram a realização de coleta ao menos uma vez na semana pelo serviço de limpeza pública.

Dos agricultores que relataram a localidade de sua propriedade, verificou-se que houve pelo menos um agricultor dos diferentes distritos rurais de Vitória da Conquista - BA, sendo: Capinal, Quilombo de Oitero, Limoeiro, Veredinha, Itapirema, Bate pé, Inhobim, Pradoso, Iguá, Caiçara, Matinha, Lagoa das Flores e Itaipu (Figura 1). A maioria $(74,1 \%)$ referiu que área da propriedade media entre 0,1 e 30 ha, apresentando cultivo diversificado de alimentos (Figura 2).
Figura 1 - Localidades rurais dos agricultores familiares participantes do estudo, abrangendo os distritos de Vitória da

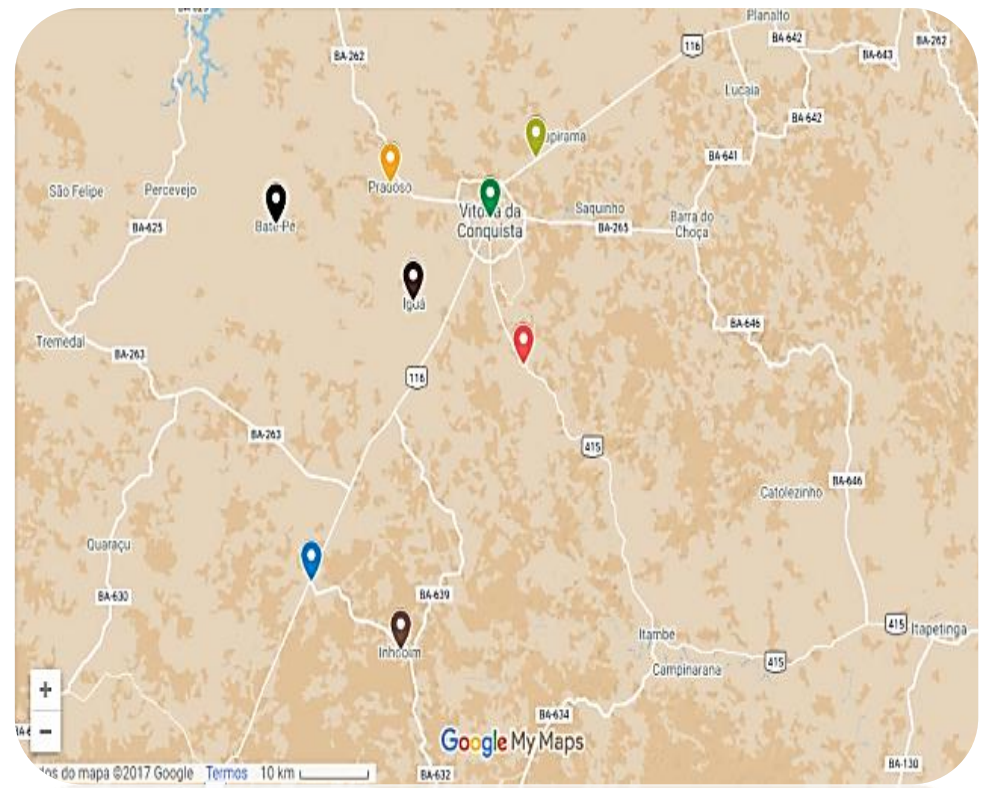

Fonte: Google My Maps (Adaptado) 
Figura 2 - Percentual de culturas produzidas pelos agricultores familiares, Município de Vitória da ConquistaBA, 2017.

\section{CULTURAS PRODUZIDAS PELOS ENTREVISTADOS}

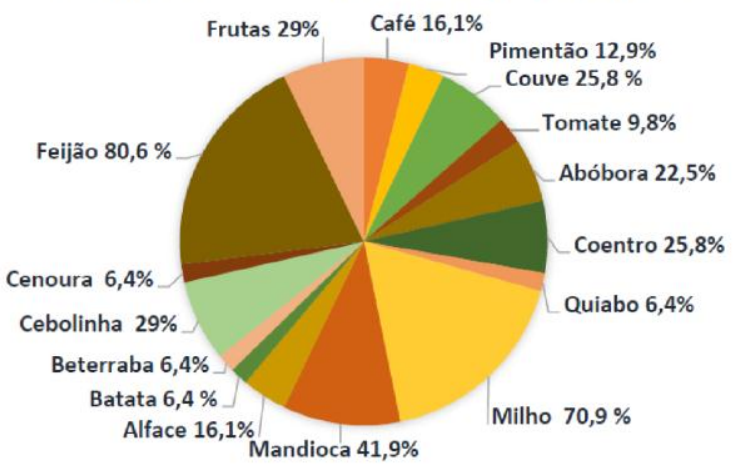

Quando questionados quanto ao uso de agrotóxicos, cerca de 29,0\% dos entrevistados afirmaram que utilizavam agrotóxicos na produção agrícola. 61,2\% dos agricultores consideraram a manipulação de agrotóxico como perigosa para saúde, 29 \% não quiseram e/ou souberam responder a esta questão e, 9,7\% não consideram o uso perigoso. Entretanto, verificou-se que apenas $38,7 \%$ acreditavam que alguns sintomas após uso de agrotóxicos podem estar relacionados com a utilização do produto, seguidos por $29 \%$ que não acreditam e, por 32,2\% que não responderam e/ou não souberam opinar. Relataram (9,7\%) também não terem tido acompanhamento médico.

$\mathrm{Na}$ Tabela 2, estão apresentadas as informações relacionadas ao uso de agrotóxico na lavoura. A principal forma de aquisição do produto pelos agricultores familiares foi por meio do receituário agronômico fornecido pelo próprio comerciante (66,7\%). Os agricultores informaram a utilização de outros produtos não elencados no formulário. Um agricultor referiu utilizar um herbicida chamado Folidol $^{\circledR}$, combatente de Hymenoptera (formigas), sendo este da classe toxicológica I ou extremamente tóxico, outros dois agricultores referiram o uso do produto denominado Mirex ${ }^{\circledR}$ e os demais relataram não se lembrar do nome comercial.

Tabela 2 - Informações relacionadas ao uso de agrotóxico na lavoura, Município de Vitória da Conquista- BA, 2017.

\begin{tabular}{|c|c|c|}
\hline Informações referentes ao uso de agrotóxico & $n=9$ & Percentual \% \\
\hline \multicolumn{3}{|l|}{ Forma de aquisição do produto } \\
\hline Engenheiro agrônomo na compra & 01 & 11,1 \\
\hline Comerciante & 06 & 66,7 \\
\hline Compra sem consultar & 02 & 22,2 \\
\hline \multicolumn{3}{|l|}{ Agrotóxico que utiliza (Nome comercial $\left.{ }^{\circledR}\right)$} \\
\hline Afalon ${ }^{\circledR}$ & 01 & 11,1 \\
\hline Dithane ${ }^{\circledR}$ & 01 & 11,1 \\
\hline Expurgran ${ }^{\circledR}$ & 01 & 11,1 \\
\hline Informaram Outro & 06 & 66,7 \\
\hline \multicolumn{3}{|l|}{ Forma de transporte até a propriedade } \\
\hline Carro com caçamba & 02 & 25 \\
\hline Carro fechado & 06 & 75 \\
\hline \multicolumn{3}{|c|}{ Local de armazenamento dos agrotóxicos na propriedade } \\
\hline Em local reservado, próprio para estes produtos & 07 & 77,8 \\
\hline A céu aberto & 02 & 22,2 \\
\hline \multicolumn{3}{|l|}{ Destino das embalagens vazias } \\
\hline Rio, córrego ou lago & 02 & 22,2 \\
\hline Guarda para usar de outro modo & 01 & 11,1 \\
\hline Deixa a céu aberto & 01 & 11,1 \\
\hline Devolve & 01 & 11,1 \\
\hline Outra forma (Queima ou Enterra) & 04 & 44,4 \\
\hline \multicolumn{3}{|l|}{ Termo que usa para se referir ao produto } \\
\hline Veneno & 07 & 77,8 \\
\hline Remédio & 01 & 11,1 \\
\hline Agrotóxico & 01 & 11,1 \\
\hline \multicolumn{3}{|l|}{ Quem orienta a aplicação } \\
\hline Agrônomo & 05 & 55,6 \\
\hline
\end{tabular}




\section{Continuação.}

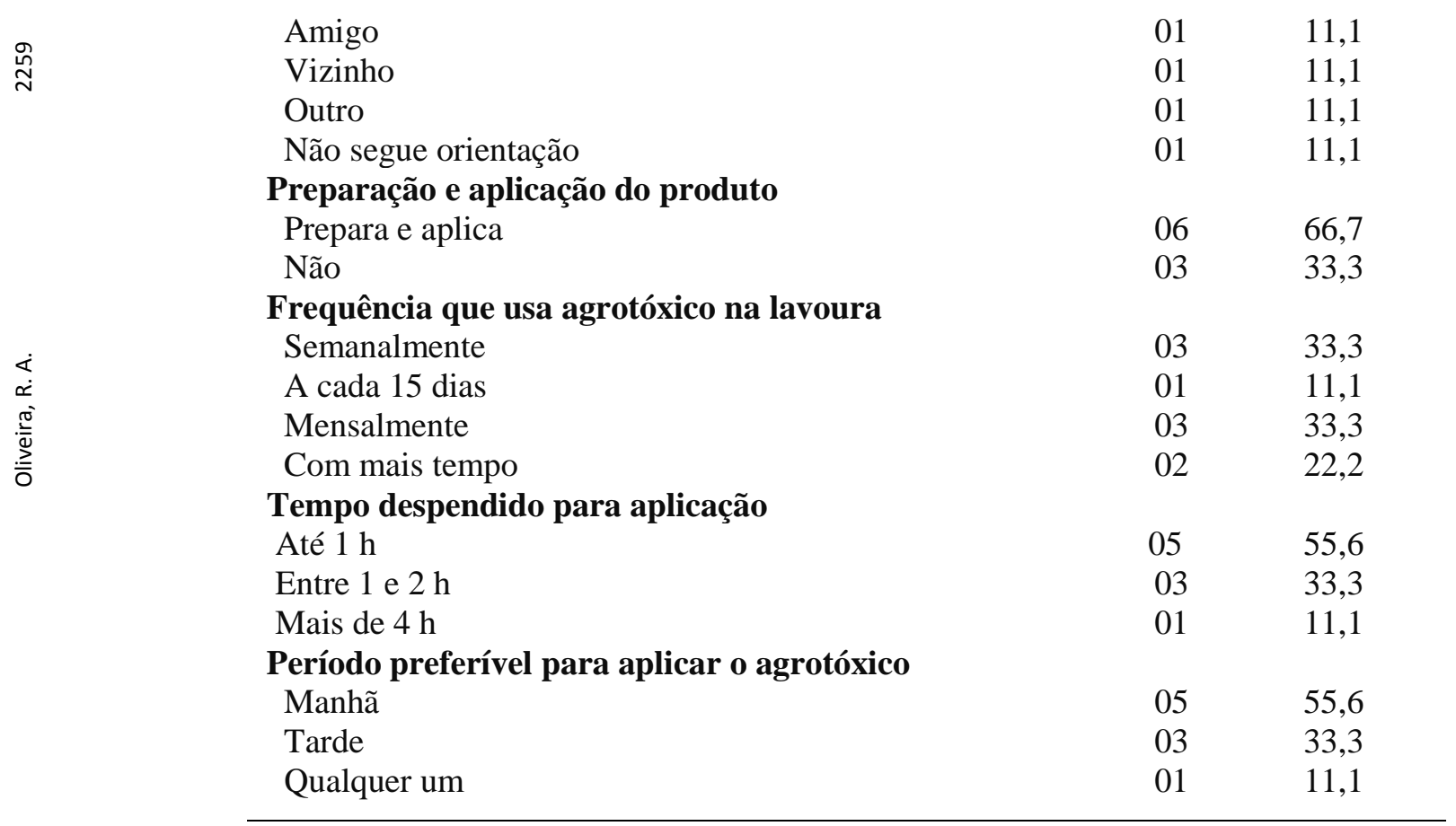

Entre os agricultores que manuseavam agrotóxico, 33,3 \%, utilizaram mais de um único tipo de produto (Tabela 2). Um dos agricultores referiu utilizar um herbicida (Afalon ${ }^{\circledR}$ ) indicado para controle de ervas daninhas nas culturas de cebola, batata e cenoura, da classe toxicológica III ou medianamente tóxico. ${ }^{20}$ Outro agricultor mencionou utilizar antifúngico (Dithane ${ }^{\circledR}$ ) para inúmeras culturas distintas, da classe toxicológica I ou extremamente tóxico, também considerado com potencial de periculosidade ambiental II. $^{21}$ Outro trabalhador rural informou uso do inseticida (Expurgran ${ }^{\circledR}$ ) em pó para controle de formigas e pulgões, da classe IV ou pouco tóxico. ${ }^{22}$

Quanto à forma de transporte do produto até a propriedade, $75 \%$ utilizavam carro próprio e fechado. Em relação ao armazenamento 77,7 \% utilizavam local reservado, próprio para estes produtos. Entretanto, quando questionados ao destino das embalagens vazias, $44,4 \%$ referiram queimar ou enterrar na propriedade (Tabela 2).

Veneno foi o termo mais empregado pelos agricultores familiares $(77,8 \%)$ que utilizaram agrotóxico. Receberam orientação de um agrônomo para aplicação do mesmo, cerca de $55,6 \%$ dos agricultores. A maioria dos agricultores também relatou que ele (a) mesmo (a) preparava e aplicava o produto $(66,7 \%)$, com frequência mensal ou semanalmente $(33,3 \%)$ a depender da necessidade e do tamanho da lavoura, sendo o tempo despendido para aplicação mais frequente em até $1 \mathrm{~h}$ e preferivelmente pela manhã $(55,6 \%)$ (Tabela 2).
Quando questionados sobre a realização de leitura do rótulo da embalagem do produto, $66,7 \%$ dos trabalhadores entrevistados informaram que nem sempre faziam a leitura do rótulo. 0 mesmo percentual $(66,7 \%)$ relatou não compreender o que sinalizam as faixas de diferentes cores nas embalagens dos produtos.

Das informações coletadas acerca do uso dos Equipamentos de Proteção Individual (EPI's), $66,6 \%$ mencionaram usar, mas de modo incompleto, sendo as botas e as máscaras os EPI's mais rotineiramente utilizados $(66,6 \%), 87,5 \%$ referiram lavar as mãos logo após aplicar o produto e/ou tomar banho em seguida $(77,7 \%)$.

Dentre os indivíduos que relataram utilizar agrotóxicos, um $(11,1 \%)$ mencionou ter apresentado intoxicação aguda.

\section{Discussão}

O município de Vitória da Conquista está localizado na região Sudoeste do Estado da Bahia, a quinhentos e nove quilômetros da capital Salvador. É um grande produtor de hortaliças por meio da agricultura familiar, apresentando também a produção de café, fruticultura, floricultura, e tubérculos. O município apresenta uma população estimada de 306.866 habitantes, inserido numa área de transição de Biomas, entre a Caatinga e Mata Atlântica. A população da área rural é de aproximadamente 32.127 habitantes, abrangendo diversos distritos (Bate-Pé, Cabeceira 
da Jiboia, Cercadinho, Dantelândia, Iguá, Inhobim, José Gonçalves, Pradoso, São João da Vitória, São Sebastião e Veredinha) ${ }^{23}$.

Perfil da população estudada e características gerais do domicílio e propriedade

O perfil da população entrevistada mostrou que a maioria dos participantes foi do sexo feminino. Em regiões onde a agricultura é de caráter familiar, as mulheres possuem maior participação no trabalho agrícola ${ }^{8}$, estando assim mais expostas a ocorrência de intoxicação, no caso de utilização de agrotóxicos. As mulheres constituem uma população mais vulnerável ao uso de agrotóxico, por apresentar níveis mais elevados de tecidos sensíveis a oscilação hormonal. ${ }^{9}$

A faixa etária dos participantes mostrou predominância entre 61 a 80 anos de idade, diferentemente de outros estudos que abordaram a mesma temática, tendo um destes a participação de indivíduos na faixa etária da população economicamente ativa, entre 18 a 49 anos. ${ }^{13}$ Este dado desperta preocupação, quando se considera que agricultores com idade mais avançada apresenta um retardo em novos processos de aprendizado. Assim, a utilização de métodos mais agroecológicos e sustentáveis na lavoura, tenderia ser mais difícil de ser estabelecida entre esses agricultores. $^{15}$ Além disso, indivíduos idosos apresentam-se com maior vulnerabilidade frente ao uso de agrotóxicos quando comparado à outras populações, muitos trabalham concomitantemente em atividades domésticas e também agrícolas configuram a população que mais adoece, incapacitando-os para o trabalho. ${ }^{24}$

O baixo nível de instrução verificado pode ser considerado um grande problema, pois dificulta a realização da leitura das recomendações gerais de segurança por parte dos trabalhadores rurais, demonstrado em vários estudos. ${ }^{3,4,6,11,16,25}$ Para àqueles que utilizam agrotóxico, considera-se um fator importante para o uso de Equipamentos de Proteção Individual (EPI's). ${ }^{13}$ A baixa escolaridade justifica a carência na compreensão das informações contidas nas embalagens, indicando que nem sempre o agricultor saberá usar a dose recomendada para sua lavoura, além de influenciar ao não uso dos EPI's. ${ }^{1,26}$

Em relação à configuração domiciliar, observa-se uma unidade familiar composta por pai, mãe e filhos, e em média, cada casal possui dois filhos, igualmente observado em outro trabalho. ${ }^{27}$
A principal forma de abastecimento de água relatada foi a rede geral de distribuição do munícipio de Vitória da Conquista/BA, haja visto que as localidades citadas fazem parte da zona rural do referido município, porém o fato de apenas $(35,4 \%)$ dos trabalhadores receberem água no domicílio através desta rede, demonstra que a cobertura do fornecimento de água ainda precisa ser ampliada. O fornecimento por meio de carro pipa pode estar associado à escassez de água nos períodos sem chuva. ${ }^{15,28}$

Os entrevistados afirmaram que tomam banho após uso do agrotóxico $(77,7 \%)$ e relataram também a utilização de poços artesianos em seus sítios e residências. Estudos descrevem um sistema diferenciado no quesito de provimento de água para as zonas rurais, ainda muitos se utilizam de pequenos açudes ou poços, tanto para a lavoura, quanto para as casas. 4,8,15,27,29

Quanto ao tratamento prévio da água utilizada para beber, foi amplamente referida a forma filtrada, porém, alguns participantes informaram que consumiam água sem nenhum tratamento. Este dado é preocupante, pois, o consumo de água in natura pode ser considerado um grave problema de saúde pública, sendo esta situação muito difundida e recorrente nas áreas rurais. $^{30}$

Das informações obtidas em relação ao destino dado ao lixo, muitos disseram fazer a queima do mesmo. Tal situação pode ser atribuída ao fato de que na zona rural, a coleta de lixo muitas vezes é inviável. ${ }^{31}$ A queima não é indicada, pois, o lixo pode conter inúmeras substâncias poluentes que, durante a combustão, são liberadas para a atmosfera, contribuindo para a poluição. ${ }^{32}$

No tocante aos limites de áreas das propriedades dos entrevistados, a maioria possui 0,1-30 ha de terra, caracterizando assim, por pequenas e médias propriedades de agricultores, tendo em vista que uma área referente a um minifúndio equivale, em média, a 19 há. ${ }^{13}$ Também é determinada pela Lei no 11.326 , de 24 de julho de 2006, a consideração de que agricultor familiar, é aquele que pratica atividades no meio rural, utilizando predominantemente, mão de obra da própria família e tendo um percentual mínimo da renda familiar originado de atividades econômicas do seu estabelecimento. ${ }^{31}$

Desta forma, os limites de áreas das propriedades relatadas no presente estudo foram constituídos por pequenos e médios agricultores 
familiares, ressaltando-se que, em propriedades pequenas, a utilização de agrotóxico tende a reter grandes quantidades de partículas destes produtos no solo, próximo ao domicílio. A depender das características geomorfológicos do solo, sendo este intemperizado, a retenção das partículas de agrotóxico pode favorecer também a contaminação da água da propriedade, potencializando os riscos de contaminação. 1,8,16,28

\section{Informações sobre o uso de agrotóxicos pelos agricultores familiares}

Dentre os entrevistados, poucos informaram utilizar agrotóxico nas lavouras. Entretanto, mesmo com a baixa frequência de entrevistados que referiram o uso de agrotóxico, nota-se que para algumas culturas, este emprego do produto é considerado necessário por quem o utiliza ${ }^{3,5}$, sendo quase que contínuo para o controle de pragas na lavoura ${ }^{13,27}$, mesmo para àqueles trabalhadores rurais que têm noção mínima dos riscos à saúde. ${ }^{1}$ Tal fato pode ser elucidado pelo estímulo ao aumento da produção, condicionando a utilização em diversas lavouras como prática predominante e hegemônica. ${ }^{4,6}$

Em relação à aquisição, comprar o agrotóxico diretamente no comércio foi o modo mais relatado pelos agricultores. Uma problemática envolvida neste processo é que, pode haver influência direta por vendedores e/ou profissionais técnicos das casas comerciais, é uma prática considerada perigosa, haja vista que ocorre incentivo das indústrias químicas para metas de vendas dos produtos e, consequentemente o precário ou não esclarecimento das informações ao agricultor familiar para uso adequado dos produtos. ${ }^{1,4,11}$ Desta maneira, a atividade de compra do produto, é considerada a primeira que determina a segurança do trabalhador rural, evitando, por conseguinte, efeitos de intoxicação. ${ }^{11}$

Ressalta-se que o agricultor familiar inserido em um modelo globalizado e moderno de produção agrícola usual, ou seja, baseado na utilização de agrotóxico para o aumento da produtividade no campo, não pode ser responsabilizado por não procurar o devido profissional para orientar a compra do produto, pois, obter o receituário agronômico nos estabelecimentos comerciais é acessível e não envolve custos adicionais para o trabalhador. ${ }^{11}$

Considerando ainda o uso de agrotóxico pelos participantes do estudo, alguns agricultores referiram utilizar agrotóxicos não relacionados no instrumento de coleta de dados. Esse dado chama atenção, pois esses inseticidas específicos para o controle de Himenópteros(formigas) são de classificação toxicológica I ou extremamente tóxico e são bem absorvidos pela via dérmica do agricultor. $^{33}$

Além disso, foi informado o uso de um único produto, independentemente da cultura alimentícia que tenha em sua propriedade. 0 agricultor que informou o uso de Folidol $^{\circledR}$ no cultivo de frutas, todavia, este agrotóxico é destinado para culturas de feijão, milho, soja, entre outros. ${ }^{18}$ Outro agricultor também informou o uso de agrotóxico não apropriado para a sua lavoura, relatou o uso do produto Afalon $^{\circledR}$ no cultivo de feijão, milho e mamão, entretanto, este agrotóxico é indicado para culturas de hortaliças como alho, cebola e cenoura. ${ }^{17}$ Este resultado indica a necessidade de utilização das Boas Práticas Agrícolas (BPA) visando oferecer ao consumidor um produto seguro.

Quanto ao transporte do agrotóxico até o domicílio, este inclui etapas para garantir a segurança de quem irá manipular o produto. ${ }^{11}$ Desta forma, o transporte considerado correto, deve ocorrer de acordo o disposto no Decreto-Lei $n^{\circ}$ 4074, de 4 de janeiro de 2002 em utilitários com carroceria aberta ou fechada. ${ }^{34}$ No presente trabalho, a forma de transporte mais referida por parte dos agricultores foi a utilização de carro próprio e fechado, devido a facilidade existente, em que o próprio agricultor familiar leva o produto ao seu domicílio, deixando de realizar a verificação com o comerciante acerca do cuidado especial para transportar os agrotóxicos adquiridos e de usar veículo adequado com caçamba externa. Essa situação descrita também foi encontrada em outro estudo. $^{33}$

Já o armazenamento dos agrotóxicos, foi referido pela maioria ocorrer em local reservado, considerado próprio para estes produtos. Esta informação é relevante e enfatiza o conhecimento dos agricultores familiares sobre a necessidade de possuir, no mínimo, um depósito separado de outras construções, em que as portas devem permanecer trancadas para evitar entrada de crianças e pessoas não autorizadas, bem como manter os produtos nas embalagens originais $\mathrm{e}$ fechadas. ${ }^{11}$ Entretanto, quanto ao destino das embalagens vazias, muitos disseram queimar ou enterrar na propriedade. O motivo da queima ou soterramento das embalagens é considerado pelos agricultores uma forma de saída para "se livrar" das embalagens vazias. ${ }^{1}$ Este hábito caracteriza-se 
como grande problema ambiental, não havendo uma prática única e adequada ao descarte das embalagens $^{27}$, em especial, acarretam a contaminação do solo e das águas subterrâneas. ${ }^{1,16} \mathrm{O}$ destino adequado das embalagens vazias dos agrotóxicos envolve a inutilização das embalagens com a perfuração do fundo para armazenamento, seguidamente da devolução de todas as embalagens vazias dos produtos na unidade de recebimento indicada pelo comerciante na nota fiscal. ${ }^{11}$

Em relação ao recebimento de orientação por um profissional técnico para aplicação do agrotóxico, este se apresentou de forma relevante. Um estudo também encontrou este mesmo padrão, referindo que a maioria dos agricultores familiares questionados havia recebido algum tipo de orientação técnica. ${ }^{6} \quad$ Nesta etapa, as informações transmitidas por um profissional da área agrícola, interferem na construção do saber do agricultor ao usar a dose recomendada para sua lavoura, bem como influencia quanto ao uso dos EPI's, diminuindo a exposição direta e, por conseguinte, intoxicações agudas. ${ }^{1,25}$ Por outro lado, um dos mais frequentes problemas quando não se tem orientação é o efeito prático do Receituário Agronômico, servindo como orientação técnica ao trabalhador rural. ${ }^{3,8}$ Diversos estudos relatam, que a maioria dos agricultores não recebeu a devida assistência técnica. ${ }^{4,16,32}$

No presente estudo, a terminologia mais recorrente pelos agricultores familiares que utilizavam agrotóxico em suas lavouras foi veneno. O emprego deste termo faz jus ao produto que é utilizado em suas lavouras ${ }^{1}$, além disso, evidencia uma maior percepção de seus efeitos à saúde humana ${ }^{13}$. Outros estudos também relataram a palavra veneno como a mais utilizada pelos entrevistados para se referirem aos agrotóxicos. $6,13,25$

\section{Abordagens sobre a exposição ocupacional}

A consideração de perigo para a saúde do trabalhador rural, envolvendo a manipulação de agrotóxicos, foi referida pela maioria dos entrevistados. Contudo, nota-se que a percepção de que os agrotóxicos podem trazer consequências para a saúde humana e ao meio ambiente não depende somente do conhecimento do agricultor e das informações contidas na embalagem do produto ${ }^{4}$, mas associa-se a possível ocorrência das intoxicações agudas, como por exemplo, pela inalação do produto. Tal fato está atribuído a "invisibilidade" dos riscos relacionados ao manejo do produto, relevando que para os entrevistados, o que não se vê não representa perigo. ${ }^{35}$

Apesar de boa parte acreditar na possível relação do aparecimento de alguns sintomas e o uso do produto, uma parcela significativa não acredita e/ou não respondeu ou opinou a respeito. Como retratado em outros trabalhos ${ }^{9,34}$, este posicionamento dos agricultores familiares deixa transparecer a minimização da provável relação de intoxicação com a utilização de agrotóxico, encarando como um processo natural decorrente do manejo.

Desta forma, uma questão agravante é a exposição não somente do agricultor e de todo seu núcleo familiar, mas também do acometimento a quem irá consumir esses alimentos possivelmente contaminados, levando a chamada intoxicação indireta, quando se ingere um alimento cujo nível residual de agrotóxico encontra-se elevado ${ }^{1}$. Muitos desses alimentos são analisados pelo Programa de Análise de Resíduos de Agrotóxicos (PARA) em Alimentos da Anvisa Sanitária ${ }^{35}$ que avalia os níveis de resíduos de agrotóxicos nos alimentos de origem vegetal que chegam à mesa do consumidor, sendo um indicador da ocorrência de resíduos de agrotóxicos em alimentos.

No último relatório do PARA referente ao primeiro ciclo do Plano Plurianual 2017-2020, foram analisadas 4.616 amostras de 14 alimentos de origem vegetal representativos da dieta da população brasileira, sendo pesquisados até 270 agrotóxicos diferentes. Do total de amostras analisadas foram consideradas insatisfatórias 1.072 amostras (23\%) em relação à conformidade com o LMR (Limite Máximo de Resíduos), estabelecido pela Anvisa. Ao detalhar o perfil dos resultados insatisfatórios, observou-se que 1.927 detecções irregulares nas amostras analisadas foram relativas a 113 agrotóxicos diferentes. Os ingredientes ativos acefato, clorpirifós e metomil foram os que apresentaram maior índice de detecções irregulares (ANVISA, 2020).

Quanto a exposição pelas atividades laborais do agricultor rural, no quesito preparação do agrotóxico, foi observado que eles mesmos realizam o procedimento, assim como também em demais estudos. ${ }^{1,4,6,13,16}$ A preparação do agrotóxico é um procedimento comum e prévio, necessária para aplicação da substância contida na embalagem do produto e envolve atividades como o enchimento do tanque e mistura do caldo, a fim de diluição; é de igual perigo quando comparado a aplicação ao manipulador. ${ }^{9}$ 
Em relação às informações prestadas quanto a aplicação, informaram também que são eles que aplicam o produto, com frequência mensal ou até semanal. Outros trabalhos demonstraram que os próprios agricultores aplicam o agrotóxico ${ }^{1,4,6,13,16}$; um deles ressalta que a frequência de aplicação do produto na lavoura é elevada e em pouco espaço de tempo. ${ }^{4} \mathrm{~A}$ aplicação é considerada necessária, pois para o agricultor, as pragas que assolam a sua lavoura precisam desaparecer. ${ }^{1}$ Além disso, a frequência curta de aplicação do agrotóxico pode ser explicada pela intensificação que ocorre no verão, devido à maior intensidade de infestação dessas pragas. ${ }^{13}$ Contudo, é na aplicação do agrotóxico que surgem os maiores problemas associado a colocar em perigo a saúde do agricultor e o meio ambiente, ocasionando a ampla exposição dos trabalhadores rurais e desconforto. ${ }^{11,16}$

Destaca-se também no presente estudo, o relato sobre a não realização de leitura do rótulo da embalagem do agrotóxico, bem como da não compreensão do que sinalizam as faixas contidas de diferentes cores pela maioria. Como já evidenciado inicialmente, o baixo nível de instrução e escolaridade verificado neste trabalho, podem ser considerados fatores que justificam a carência na compreensão das informações contidas nas embalagens. 1,3,4,6,11,16,24,25

A leitura dos rótulos e a compreensão do processo de preparação e utilização de agrotóxicos na lavoura seriam condições indispensáveis para o manejo e a aplicação desses produtos de forma segura ao agricultor familiar, mitigando assim os possíveis danos à saúde e ao ambiente decorrentes desse uso ${ }^{8}$. Além de que, nesta etapa do manejo de agrotóxicos, os trabalhadores rurais, ao aplicarem doses altamente tóxicas, quase sempre sem os completos equipamentos de proteção, podem se intoxicarem. ${ }^{1}$

O uso incompleto dos EPI's informado pelos entrevistados é considerado como um agravante a exposição de risco. O fato da não utilização dos EPI's de modo completo, pode estar associado à percepção subjetiva de toxicidade do produto para a saúde ${ }^{33}$, além de muitas vezes, alegarem a carestia, a falta de costume, bem como o desconforto e incomodo pelo calor como motivos. 13,27,32,34 Outros estudos também apresentaram relatos do não uso dos equipamentos de proteção individual de forma completa para preparar e aplicar o agrotóxico. 1,4,6,13,25,32,33

Outra informação relevante referente a exposição, foi o relato de que nenhum agricultor utiliza roupas impermeáveis, ocorrência, também relatada em outro estudo que abordou temática semelhante. ${ }^{23}$ É sabido que o uso de equipamento de proteção individual objetiva a segurança quanto à exposição acidental aos agrotóxicos haja vista que a chance de um indivíduo ter algum problema de saúde diminui. ${ }^{13}$ Uma implicação da não utilização de roupas impermeáveis é a possível intoxicação pela via dérmica considerando que, inevitavelmente, qualquer respingo de produto atinja a pele do agricultor ${ }^{11}$.

\section{Considerações finais}

A população estudada, constituída principalmente por mulheres e idosos, configurando-se grupos mais vulneráveis ao uso de agrotóxicos. E, o baixo nível de escolaridade da população estudada, implica na deficiência da compreensão dos métodos de segurança laboral a serem adotados previamente à aplicação do produto.

O agrotóxico é considerado imprescindível por quem o utiliza para controle de pragas, visando - aumento da produtividade das culturas de alimentos. E, a forma de aquisição deste produto é feita diretamente através do comerciante, o que pode levar a utilização exacerbada e inapropriada nos alimentos que são produzidos.

Agrotóxicos utilizados para controle de formigas, não são considerados perigosos para a saúde do trabalhador, apontando a falta de conhecimento da elevada toxicidade do produto pelos agricultores.

O transporte do agrotóxico para propriedade realizado em veículo próprio, mostrando não haver nenhuma fiscalização para este tipo de procedimento.

O conhecimento de guardar as embalagens em local reservado é destacado pela percepção da necessidade em evitar a exposição de outras pessoas e animais ao produto, contudo, não foi observado noção de preocupação com meio ambiente, associada a queima das embalagens vazias e também pela contaminação do solo, advinda do uso de agrotóxicos.

O recebimento de orientação para aplicação de agrotóxico auxilia na sensibilização acerca dos riscos para quem os utilizam rotineiramente. Associado a isso, observou-se que o termo veneno foi o mais utilizado para se referir ao produto.

Existem deficiências na percepção do agricultor familiar quanto ao uso e manejo dos agrotóxicos. E a consideração de perigo para a saúde está atrelada a ocorrência de sintomas agudos, denotando que o perigo não visível aos olhos do trabalhador rural, pode denotar que possivelmente não existam problemas decorrentes 
da utilização, principalmente pelo não uso dos EPI's na preparação e aplicação do agrotóxico.

O número de indivíduos que referiram utilizar agrotóxicos nas plantações $(29,0 \%)$ ficou abaixo da metade do total de entrevistados. Isso indica que possa ter havido uma subnotificação na tentativa de ocultar o uso, ou esteja ocorrendo a prática de agricultura sustentável.

Ressalta-se ainda que os dados obtidos refletem informações fornecidas em um determinado momento, estando sujeitos a fatores temporais e socioculturais que possam interferir em futuras observações.

Mesmo com algumas limitações, este trabalho apresentou resultados importantes, destacando problemas ainda persistentes no campo em relação ao nível de conhecimento de agricultores familiares sobre o uso de agrotóxicos, sendo esta pesquisa base para planejamento de estudos futuros mais amplos nessa temática. Aponta também para necessidade de realização de ações de intervenção local com estratégias de Educação em Saúde.

\section{Referências}

1. Leite KC, e Torres MBR. O uso de agrotóxicos pelos trabalhadores rurais do assentamento catingueira Baraúna-RN. Revista verde de agroecologia e desenvolvimento sustentável. 2008;3(4):06-28.

2. Rigotto, RM, Carneiro FF, Marinho AMCP, Rocha MM, Ferreira MJM, Pessoa VMP, et al. O verde da economia no campo: desafios à pesquisa e às políticas públicas para a promoção da saúde no avanço da modernização agrícola. Ciência \& Saúde Coletiva. 2012;17(06):1533-42.

3. Faria NMX, Fassa AG e Facchini LA. Intoxicação por agrotóxicos no Brasil: os sistemas oficiais de informação e desafios para realização de estudos epidemiológicos. Ciência \& Saúde Coletiva. 2007;12(1):25-38.

4. Preza DLC e Augusto, LGS. Vulnerabilidades de trabalhadores rurais frente ao uso de agrotóxicos na produção de hortaliças em região do Nordeste do Brasil. Rev Brasil Saúde Ocupac. 2012;37(125):89-98.

5. Nasrala Neto E, Lacaz, FAC e Pignati WA. Vigilância em saúde e agronegócio: os impactos dos agrotóxicos na saúde e no ambiente. Perigo à vista! Revista Ciência \& Saúde Coletiva.2013;19(12).

6. Alencar LD, Neto Pereira JR, Alencar LD, Barbosa EM e Souza AS. Uso indiscriminado de agrotóxicos no projeto de irrigação das Várzeas de Sousa-PB. Revista Verde de Agroecologia e Desenvolvimento Sustentável. 2014;9(4):117-122.
7. Midio AF e Martins DI. Toxicologia dos alimentos. São Paulo: SP; 2000.

8. Rangel CDF, Sarcinelli PDN e Rosa ACS. Uso de agrotóxicos e suas implicações na exposição ocupacional e contaminação ambiental. Cad. saúde colet. 2011.

9. Mello CMD e Silva LF. Fatores associados à intoxicação por agrotóxicos: estudo transversal com trabalhadores da cafeicultura no sul de Minas Gerais. Epidemiologia e Serviços de Saúde. 2013;22(4):609-620.

10. Brasil. Sistema Nacional de Informações Tóxico-Farmacológicas (SINITOX). Rio de Janeiro: Fiocruz; $2017 . \quad$ Disponível em: http://sinitox.icict.fiocruz.br/dados-de-agentestoxico. Acesso em 01 fev 2021.

11. Abreu PHB e Alonzo HGA. Trabalho rural e riscos à saúde: uma revisão sobre o" uso seguro" de agrotóxicos no Brasil. Revista Ciência \& Saúde Coletiva. 2014;19(10).

12. Forget $O$. Pesticides, necessary but dangerous poisons. New York; 1989.

13. Gilson, IK, Rocha, LG, Silva, MRV, Wammes, SW, Leite, S, Welter, T,LC. Agrotóxicos liberados nos anos de 2019-2020: Uma discussão sobre a uso e a classificação toxicológica. Brazilian Journal of Development. 2020. 6(7).

14. Lopes, EV, Padilha, NS. Retrocessos no sistema de comunicação de riscos na rotulagem de agrotóxicos: a classificação da ANVISA. Revista de Direito Ambiental e Socioambientalismo. 2019; 5(2), 55-76.

15. Jacobson LSV, Hacon SS, Alvarenga L, Goldstein RA, Gums C., Buss DF et al. Comunidade Pomerana e uso de agrotóxicos: uma realidade pouco conhecida. Revista Ciência \& Saúde Coletiva. 2009;14(6).

16. Lei $6.746 / 79$, Pub Diário Oficial da União (Dez 10, 1979).

17. Vital T e Sampaio Y. Agricultura familiar e fruticultura irrigada: estudos de caso no nordeste. Anais da Academia Pernambucana de Ciência Agronômica. 2014;4:275-290.

18. Bedor CNG, Ramos LO, Pereira PJ, Rêgo MAV, Pavão AC e Augusto LGDS. Vulnerabilidades e situações de riscos relacionados ao uso de agrotóxicos na fruticultura irrigada. Rev Bras Epidemiol. 2009; 12(1): 39-49.

19. Pesquisa Nacional de Saúde - PNS. Questionário do Domicílio. [internet] 2010. [atualizada em: 2017 Abr 26; acesso em: 2016 Jun 16]. Disponível em: http://www.pns.icict.fiocruz.br/arquivos/ Domiciliar/Modulo\%20A-PNS.pdf

20. Bula Afalon ${ }^{\circledR} 450$ SC. [atualizada em: 2017 Abr 26; acesso em: 2017 Abr 16]. Disponível em: 
http://www.adapar.pr.gov.br/arquivos/File/defis/ DFI/Bulas/Herbicidas/afalon450sc_1.pdf

21. Bula Dithane ${ }^{\circledR}$ NT. [atualizada em: 2017 Abr 26; acesso em: 2017 Abr 16]. Disponível em: http://www.adapar.pr.gov.br/arquivos/File/defis/ DFI/Bulas/Fungicidas/dithane.pdf

22. Bula Expurgran ${ }^{\circledR}$. [atualizada em: $2017 \mathrm{Abr}$ 26; acesso em: 2017 Abr 16]. Disponível em: http://www.adapar.pr.gov.br/arquivos/File/defis/ DFI/Bulas/Inseticidas/malathion_1000_ec.pdf

23. Instituto Brasileiro de Geografia e Estatística (IBGE). Vitória da Conquista: IBGE; 2012. Disponível em: <https://cidades.ibge.gov.br/brasil/ba/vitoria-daconquista/panorama>. Acesso em Acesso em: 03 fev. 2021.

24. Bastos VVS e Ferreira RP. A AGRICULTURA FAMILIAR E SUA RELAÇÃO COM O SINDICATO DE TRABALHADORES RURAIS (UM ESTUDO DE CASO). Simpósio Reforma Agrária.2016:1-8. [atualizada em: 2017 Abr 26; acesso em: 2016 Out 14]. Disponível em: https://view.officeapps.live.com/op/view.aspx?src =http://www.simposioreformaagraria.propp.ufu.br /trabalhos/grupo3/1.doc

25. Oliveira MLF e Zambrone FAD. Vulnerabilidade e intoxicação por agrotóxicos em agricultores familiares do Paraná. Ciência, Cuidado e Saúde. 2008; 5:99-106.

26. Lopes FG, Nascimento DM, Rodrigues MHBS, Nascimento SS e SIQUEIRA EDC.Avaliação do conhecimento dos agricultores (as) quanto aos riscos dos agrotóxicos e os cuidados com o seu uso. Cadernos de Agroecologia. 2016;10(3).

27. Bohner TOL, Araújo, LEB e Nishijima T. O impacto ambiental do uso de agrotóxicos no meio ambiente e na saúde dos trabalhadores rurais. Revista Eletrônica do Curso de Direito da UFSM.2013; 8:329-341.

28. Schneider S, Conterato MA, Koppe LR e Silva, CD. A pluriatividade e as condições de vida dos agricultores familiares do Rio Grande do Sul. A diversidade da agricultura familiar Editora da UFRGS. 2016;137-164.

29. Lacerda NB e Oliveira TS. Agricultura irrigada e a qualidade de vida dos agricultores em perímetros do Estado do Ceará, Brasil. Revista Ciência Agronômica. 2008;38(2):216-223.

30. Veiga, MM, Silva DM, Veiga LBE e Faria, MVC. Análise da contaminação dos sistemas hídricos por agrotóxicos numa pequena comunidade rural do Sudeste do Brasil. Cad. Saúde Pública. 2006;22(11):2391-99.

31. Lemos CA e Guerra T. Aspectos dos usos da água, agrotóxicos e percepção ambiental no meio rural, Maquiné, RS, Brasil. GEOGRAFIA (Londrina). 2004;13(2):103-116.

32. Pinheiro DK e Deboni L. O que você faz com seu lixo? Estudo sobre a destinação do lixo na zona rural de Cruz Alta/RS-Passo dos Alemães. Electronic Journal of Management, Education and Environmental Technology (REGET). 2006;1(1):13-21.

33. Lei. 11.326/2006, Pub Diário Oficial da União (Jul 24, 2006).

34. Delgado IF e Paumgartten FJR. Intoxicações e uso de pesticidas por agricultores do Município de Paty do Alferes, Rio de Janeiro, Brasil. Cad Saude Publica. 2004:180-186.

35. Zorzetti J, Neves PMOJ, Santoro PH e Constanski KC. Conhecimento sobre a utilização segura de agrotóxicos por agricultores da mesorregião do Norte Central do Paraná. Semina: Ciências Agrárias. 2014;35(4):2415-27.

36. Fonseca MDGU, Peres F, Firmo JOA e Uchôa E. Percepção de risco: maneiras de pensar e agir no manejo de agrotóxicos. Ciência \& saúde coletiva. 2007;12(1):39-50.

37. Brasil. Programa de Análises de Resíduos de Agrotóxicos em Alimentos (PARA), Relatório 2017-2020. Brasília: Anvisa; 2020. Disponível em: https://www.gov.br/anvisa/ptbr/assuntos/agrotoxi cos/programa-de-analise-de-residuos-emalimentos/arquivos/3770json-file-1. Acesso em: 03 fev. 2021. 


\section{Endereço para Correspondência}

Raíssa Amaral Oliveira

Unidade de Ensino Municipal Conveniada Ensino Militar.

Rua Régis Pachêco, S/N - Centro. Barra do Choça

$-B A$

CEP: $45.120-000$

E-mail: biocienciasraissa@gmail.com

Recebido em 24/02/2021

Aprovado em 04/08/2021

Publicado em 27/09/2021 